Article

\title{
Dynamic Modelling and Experimental Characterization of a Self-Powered Structural Health-Monitoring System with MFC Piezoelectric Patches ${ }^{\dagger}$
}

\author{
Gianpietro Di Rito ${ }^{1, * \mathbb{D}}$, Mario Rosario Chiarelli ${ }^{1}$ and Benedetto Luciano ${ }^{2}$ \\ 1 Dipartimento di Ingegneria Civile ed Industriale-Università di Pisa, 56122 Pisa, Italy; \\ mario.rosario.chiarelli@unipi.it \\ 2 AESIS srl, 56017 San Giuliano Terme (PI), Italy; b.luciano@aesis-studio.it \\ * Correspondence: gianpietro.di.rito@unipi.it \\ + This manuscript is extension version of the conference paper: Di Rito, G., Luciano, B., Chiarelli, M.R., \\ Galatolo, R. Condition monitoring of a morphing laminate with MFC piezoelectric patches via model-based \\ approach. In proceedings of the 2019 IEEE 5th International Workshop on Metrology for AeroSpace, Torino, \\ Italy, 19-21 June 2019.
}

Received: 23 November 2019; Accepted: 7 February 2020; Published: 11 February 2020

check for updates

\begin{abstract}
The paper deals with theoretical and experimental studies for the development of a self-powered structural health monitoring (SHM) system using macro-fiber composite (MFC) patches. The basic idea is to integrate the actuation, sensing, and energy harvesting capabilities of the MFC patches in a SHM system operating in different regimes. As an example, during flight, under the effects of normal structural vibrations, the patches can work as energy harvesters by maintaining or restoring the battery charge of the stand-by SHM electronic board; on the other hand, if relevant/abnormal loadings are applied, or if local faults produce a noticeable stiffness variation of the monitored component, the patches can act as sensors for the power-up SHM board. During maintenance, the patches can then work as actuators, to stress the structure with pre-defined load profiles, as well as sensors, to monitor the structural response. In this paper, the investigation, based on the electromechanical impedance technique, is carried out on a system prototype made of a cantilevered composite laminate with six MFC patches. A high-fidelity nonlinear model of the system, including the piezoelectric hysteresis of the patches and three vibration modes of the laminate beam, is presented and validated with experiments. The results support the potential feasibility of the system, pointing out that the energy storage can be used for recharging a 3V-65mAh Li-ion battery, suitable for low-power electronic boards. The model is finally used to characterize a condition-monitoring algorithm in terms of false alarms rejection and vulnerability to dormant faults, by simulating built-in tests to be performed during maintenance.
\end{abstract}

Keywords: structural monitoring; health-management; piezoelectricity; actuators; sensors; energy harvesters; modeling; testing

\section{Introduction}

Piezoelectric materials are widely used in a variety of aerospace applications in both sensing and low-power actuation devices, and many research works discuss the use of such materials as actuators, sensors, or energy harvesters. An extensive literature documents the applications of piezoelectric actuators, with special focus on noise abatement and control [1-4], the design of smart mechanical systems [5,6], the development of self-shaping structures with vibration control capabilities [7-9], or 
the design of smart devices for aerodynamic flow control [10-16]. Important research works also focus on the study of the energy harvesting capability of piezoelectric materials [17-20], as well as on their application as sensors in structural health monitoring (SHM) systems [21-25]. A relevant example of piezoelectric devices is the macro-fiber composite (MFC), which consists of rectangular piezo-ceramic rods sandwiched between layers of adhesive films containing tiny electrodes [26,27]. The electrodes transfer a voltage directly to and from ribbon-shaped rods with thickness of a few tenths of a millimeter (Figure 1).

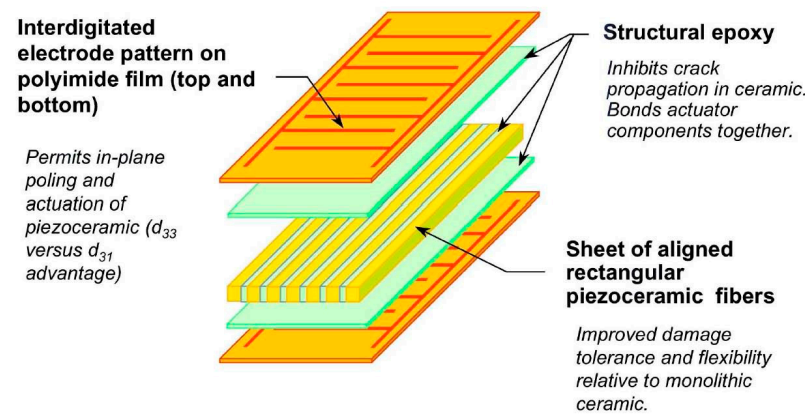

(a)

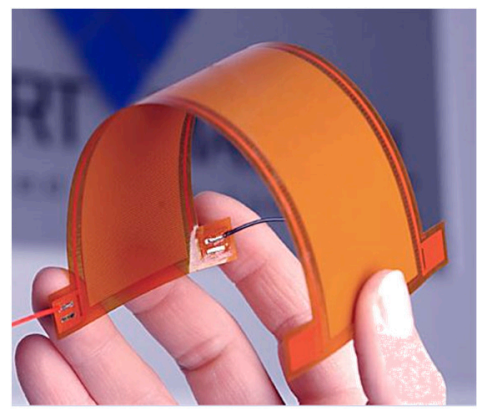

(b)

Figure 1. Macro-fiber composite (MFC) piezoelectric devices [27]: (a) structural arrangement; (b) patch layout.

With reference to actuation capabilities, the MFC technology shows better performance and durability compared to other piezo-ceramic solutions, and can be used for both high and low frequency applications [28-30]. In the aerospace field, significant research efforts have been made on high frequency applications, with particular reference to vibration control [31,32] and wing ice protection systems [33]. In the low frequency domain, an interesting and challenging application is instead related to the so-called "morphing wings" (i.e., wing structures with the capability to dynamically modify their aerodynamic shape, to enhance efficiency, and/or to control the flight loads). Suitable and promising solutions were investigated by using MFC patches co-cured in or glued on substrates of composite material [34-37].

MFC piezoelectric devices also have relevant potentialities as sensors, and a strong interest is growing in the aerospace field for their application in SHM or health usage and monitoring systems (HUMS). Relevant research efforts have been made for developing HUMS for aerospace structures with embedded, distributed, and miniature PZT devices, taking advantage from the capability of integration in complex geometries as well as to detect hidden damages [21-25,38-40]. In addition, special attention has been dedicated to the potential self-powered characteristics of these systems [41-44], bringing to promising SHM solutions with airplane structures integrating MFC patches [45] (Figure 2). Nevertheless, literature information and research results are currently poor if stand-alone devices are addressed.

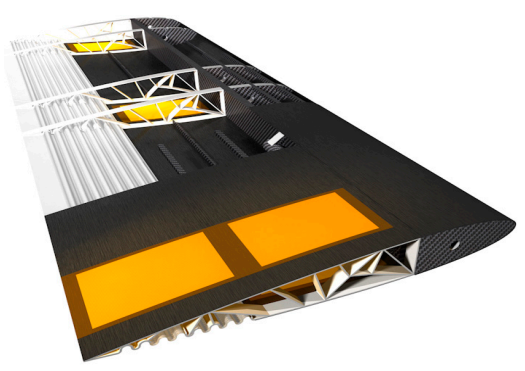

Figure 2. Example of integration of MFC patches in a wing structure [37]. 
This paper aims to provide a contribution within this research framework, with particular reference to the design of an electromechanical impedance-based SHM system [21-24] operating in different regimes. During flight, when normal loadings are applied, the patches work as energy harvesters by maintaining or restoring the battery charge of the stand-by SHM electronic board. If relevant or abnormal loadings occur, the patches instead act as sensors for the power-up SHM board, by acquiring in real-time relevant data on the component usage. Finally, during maintenance, the patches, operated by external high-voltage electronic equipment, can work as actuators, to stress the structure with pre-defined load profiles, as well as sensors, to monitor the structural response. It is worth noting that the vibration and/or loading levels strongly depend on the vehicle category (small or large airplane, turboprop or turbojet engines, helicopters, missiles, etc.) as well as on system location on the vehicle itself. Thus, the loading thresholds for the SHM board activation are expected to strongly depend on the reference application. Since this study is not focused on a particular aerospace case, the specifications/characteristics of loadings are not quantitatively given.

The work is articulated into three sections: in the first, the test rig used for the experimental characterization of the reference prototype is illustrated; successively, a model of the system dynamics is presented and validated against experimental data; finally, a model-based condition-monitoring algorithm is described and verified, by simulating different levels of system performance deviations.

\section{Experimental Test System}

As a reference structural element for the SHM studies, a carbon-epoxy composite laminate 400 $\times 45 \times 2 \mathrm{~mm} \times \mathrm{mm} \times \mathrm{mm}$ is selected (Figure $3 \mathrm{a}$ and Table 1 ). Six MFC patches are installed and symmetrically arranged on the specimen (three per side), and the laminate is cantilevered to the rig frame. The patches are electrically connected and signaled to obtain a uniform distribution of bending torque along the laminate: the three patches on each side are connected in parallel and controlled by a dedicated channel, so that they are driven by opposite voltage levels.

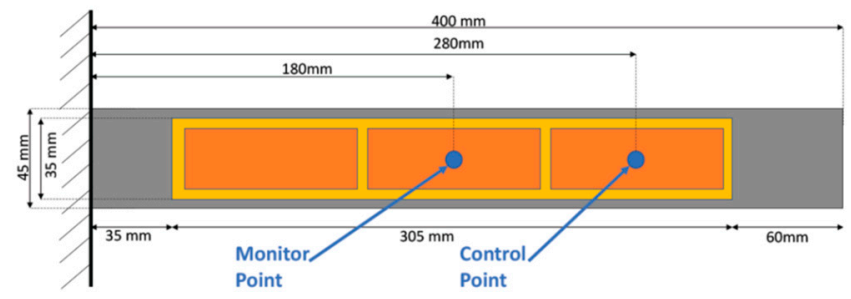

(a)

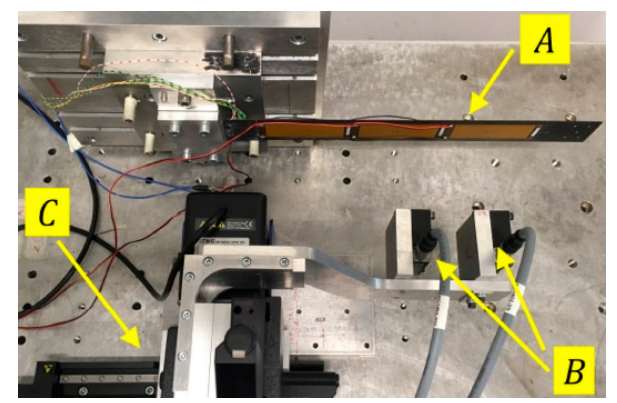

(b)

Figure 3. Experimental set-up [40]: (a) morphing laminate with MFC patches; (b) rig top view: MFC laminate (A); external laser sensors (B); precision translation stage (C).

Table 1. MFC patch operational parameters.

\begin{tabular}{ccc}
\hline Parameter & Unit & Value \\
\hline Voltage demand range & $\mathrm{V}$ & $-500 ; 1500$ \\
Temperature operating range & ${ }^{\circ} \mathrm{C}$ & $-20 ; 80$ \\
Operational frequency range & $\mathrm{kHz}$ & $\mathrm{DC} ; 10$ \\
Stall force (tensile stress) & $\mathrm{N}$ & 454 \\
Free strain & $\mathrm{ppm}$ & 1800 \\
Lifetime @ 1 kV peak-to-peak & cycles & $10^{9}$ \\
\hline
\end{tabular}

The developed test system has two basic operating modes (Figure 4): 
- $\quad$ Actuation mode (see black flows in Figure 4), in which the CRio embedded controller (B) receives from the user workstation (A) the demand voltages for the two channels of the morphing laminate, and a high-voltage amplifier (C) provides the MFC patches (D) with the electrical power;

- Sensing/energy harvesting mode (see red flows in Figure 4), in which the CRio embedded controller (B) receives from the user workstation (A) the demand vibration level for the modal shaker $(\mathrm{G})$ connected to the laminate attachment, and a multimeter $(\mathrm{F})$ measures the voltage generated by the MFC patches (D).

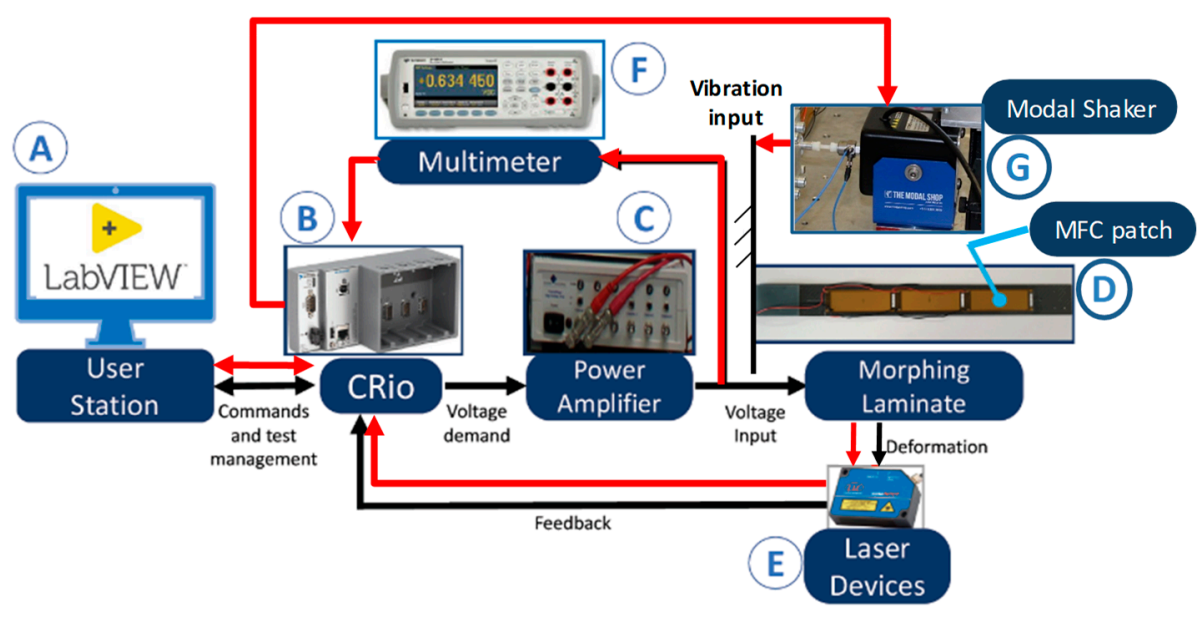

Figure 4. Experimental test system architecture.

The rig is also equipped with two laser sensors (E, in Figure 4), measuring the laminate deflections at two points (Figure $3 b$ ) to supervise the deformation as well as to reconstruct the morphed shape. The measurement points on the laminate can be adjusted or modified by means of a precision translation stage installed on the rig (Figure $3 b$ ).

\section{Development and Validation of the Model of System Dynamics}

\subsection{Dynamic Modelling}

The results of a preliminary study carried out by the authors on the prototype [40] demonstrated that the system dynamics is characterized by well-separated behaviors in the low-frequency $(<0.1$ $\mathrm{Hz}$ ) and medium/high-frequency (from 1 to $100 \mathrm{~Hz}$ ) ranges. In particular, the low-frequency range is dominated by hysteresis, while at high frequencies the system's response is characterized by structural resonances related to bending modes.

For these reasons, by taking into account the electrical and structural symmetry of the prototype, the dynamic modelling was developed with reference to the lumped-parameters scheme, shown in Figure 5, to include:

- three bending vibration modes of the laminate;

- the charge dynamics of the three couples of MFC patches, taking account of the piezoelectric hysteresis. 


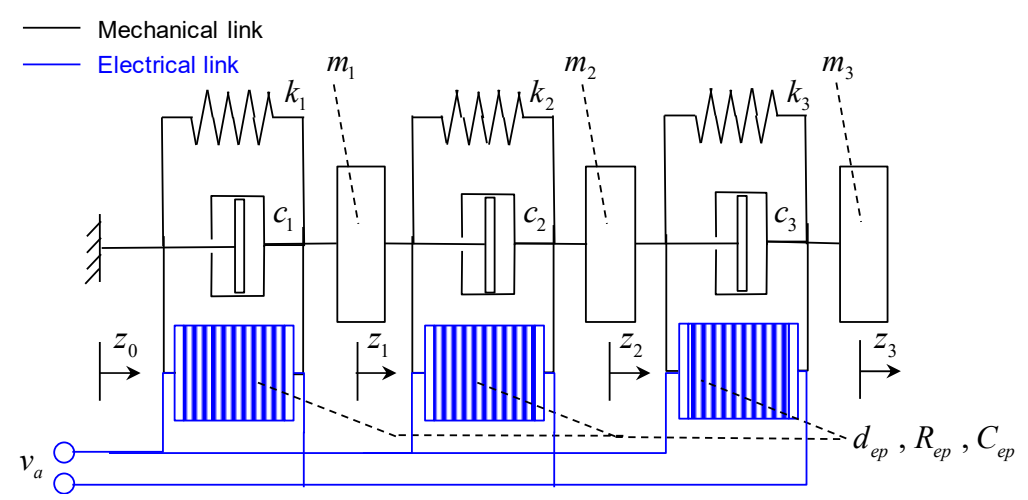

(a)

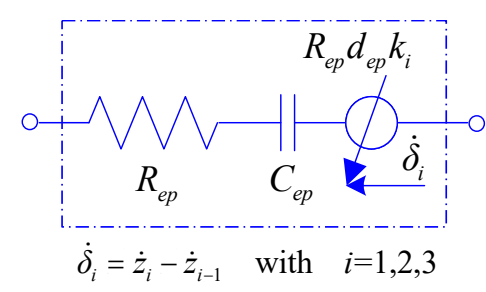

(b)

Figure 5. Lumped-parameters schematization: (a) complete prototype; (b) $i$-th patch.

Concerning the hysteresis modelling, several formulations are available in the literature to describe the phenomenon, and they are classified into two categories: static and dynamic models, depending on the use or not of ordinary differential equations (ODE) in the models themselves. Static models (e.g., Preisach [46], Prandtl-Ishlinskii [47], or polynomial models [48]) are typically very accurate, but they need a large number of experimental data for algebraic manipulations and interpolations, and their use for real-time condition monitoring is problematic [49]. On the other hand, dynamic models (e.g., Duhem [50], Maxwell [51], or Bouc-Wen [52,53] models) are often less accurate, but more adequate for control and real-time monitoring purposes. By selecting a Bouc-Wen hysteresis model, the system dynamics is described by the nonlinear twelfth-order ODE given by Equation (1),

$$
\left\{\begin{array}{l}
m_{3}\left(\ddot{\delta}_{3}+\ddot{\delta}_{2}+\ddot{\delta}_{1}\right)=-c_{3} \dot{\delta}_{3}-k_{3} \delta_{3}+\frac{k_{3} d_{e p}}{C_{e p}} q_{h 3}-m_{3} \ddot{z}_{0} \\
m_{2}\left(\ddot{\delta}_{2}+\ddot{\delta}_{1}\right)=-c_{2} \dot{\delta}_{2}-k_{2} \delta_{2}+c_{3} \dot{\delta}_{3}+k_{3} \delta_{3}+\frac{k_{2} d_{e p}}{C_{e p}} q_{h 2}-\frac{k_{3} d_{e p}}{C_{e p}} q_{h 3}-m_{3} \ddot{z}_{0} \\
m_{2} \ddot{\delta}_{1}=-c_{1} \dot{\delta}_{1}-k_{1} \delta_{1}+c_{2} \dot{\delta}_{2}+k_{2} \delta_{2}+\frac{k_{1} d_{e p}}{C_{e p}} q_{h 1}-\frac{k_{2} d_{e p}}{C_{e p}} q_{h 2}-m_{3} \ddot{z}_{0} \\
R_{e p} \dot{q}_{i}=-\alpha_{h} q_{i} / C_{e p}-R_{e p} k_{i} d_{e p} \dot{\delta}_{i}+v_{a} \\
\dot{h}_{q i}=A_{h} \dot{q}_{i}-\beta_{h}\left|\dot{q}_{i}\right|\left|h_{q i}\right|^{n-1} h_{q i}-\gamma_{h} \dot{q}_{i}\left|h_{q i}\right|^{n} \quad \text { with } i=1,2,3
\end{array}\right.
$$

where (with $i=1,2,3$ )

$$
\begin{gathered}
q_{h i}=\alpha_{h} q_{i}+\left(1-\alpha_{h}\right) h_{q i} \\
\delta_{i}=z_{i}-z_{i-1}
\end{gathered}
$$

In Equations (1)-(3), $\ddot{z}_{0}$ is the base acceleration, $z_{i}$ and $\delta_{i}$ are the displacement and the bending deformation of the $i$-th laminate section; $m_{i}, k_{i}$, and $c_{i}$ are the mass, the stiffness, and the structural damping of the $i$-th section of the laminate; $R_{e p}, C_{e p}$, and $d_{e p}$ are the equivalent resistance, capacitance, and piezoelectric coefficient of the patches; $A_{h}, \alpha_{h}, \beta_{h}, \gamma_{h}$, and $n$ are the Bouc-Wen model parameters; while $q_{i}, h_{q i}$, and $q_{h i}$ are the linear, the hysteretic, and the total charge of the $i$-th patch. Finally, $v_{a}$ depending on the operation regime of the system, represents the input voltage applied to the patches or the output voltage provided by them.

\subsection{Experimental Validation of the Model}

Aiming to collect the system identification database, the dynamics of the system prototype was experimentally characterized via an extensive test campaign, in terms of both time-domain and frequency-domain responses. The system response exhibited very good repeatability and the identification was developed in two main steps [54]: 
- estimation of the model parameters (Table 2) by minimizing the model deviations from the hardware behavior with reference to sinusoidal frequency response tests, i.e.,

- deformation responses to voltage inputs, with amplitudes from 150 to $600 \mathrm{~V}$, ranging from 0.1 to $50 \mathrm{~Hz}$, for a total of 120 tests and 200 simulations (Figure 6a);

- stored voltage responses to acceleration inputs of amplitudes from 0.01 to $0.1 \mathrm{~g}$, ranging from 1 to $50 \mathrm{~Hz}$, for a total of 120 tests and 200 simulations (Figure 6b).

- model validation, by characterizing the model deviations from the hardware behavior with reference to time response tests, i.e.,

quasi-static deformation responses to high-amplitude/low-frequency sinewave voltage inputs (Figure 7a);

$\bigcirc \quad$ transient deformation responses to step voltage inputs (Figure $7 \mathrm{~b}$ ).

Table 2. Dynamic model parameters (identification method legend: TM, test measurement; MEM, model error minimization; LA: literature assumption from [54]).

\begin{tabular}{ccccc}
\hline Symbol & Definition & Unit & Value & Identification Method \\
\hline$R_{e p}$ & Patch resistance & $\mathrm{Ohm}$ & 1500 & $\mathrm{TM}$ \\
$C_{e p}$ & Patch capacitance & $\mathrm{F}$ & $1.0610^{-5}$ & $\mathrm{TM}$ \\
$d_{e p}$ & Patch piezoelectric coefficient & $\mathrm{m} / \mathrm{V}$ & $1.3710^{-5}$ & $\mathrm{MEM}$ \\
$m_{1}$ & Mass of the root section of the laminate & $\mathrm{kg}$ & $1.1610^{-3}$ & $\mathrm{TM}$ \\
$m_{2}$ & Mass of the intermediate section of the laminate & $\mathrm{kg}$ & $2.3210^{-3}$ & $\mathrm{TM}$ \\
$m_{3}$ & Mass of the tip section of the laminate & $\mathrm{kg}$ & $1.3910^{-3}$ & $\mathrm{TM}$ \\
$k_{1}$ & Stiffness related to root section bending & $\mathrm{N} / \mathrm{m}$ & 332.98 & $\mathrm{MEM}$ \\
$k_{2}$ & Stiffness related to intermediate section bending & $\mathrm{N} / \mathrm{m}$ & 125.40 & MEM \\
$k_{3}$ & Stiffness related to tip section bending & $\mathrm{N} / \mathrm{m}$ & 21.28 & MEM \\
$c_{1}$ & Damping related to root section bending & $\mathrm{N} \mathrm{s} / \mathrm{m}$ & 0.098 & MEM \\
$c_{2}$ & Damping related to intermediate section bending & $\mathrm{N} \mathrm{s} / \mathrm{m}$ & 0.020 & MEM \\
$c_{3}$ & Damping related to tip section bending & $\mathrm{N} \mathrm{s} / \mathrm{m}$ & 0.025 & MEM \\
$\alpha_{h}$ & Bouc-Wen linearity factor & - & 0.605 & MEM \\
$A_{h}$ & Bouc-Wen dissipation gain & - & -1 & LA \\
$n$ & Bouc-Wen shape factor & - & 1 & LA \\
$\beta_{h}$ & Bouc-Wen shape factor & $\mathrm{V}-\mathrm{n}$ & 8.307 & MEM \\
$\gamma_{h}$ & Bouc-Wen shape factor & 0 & LA \\
\hline
\end{tabular}

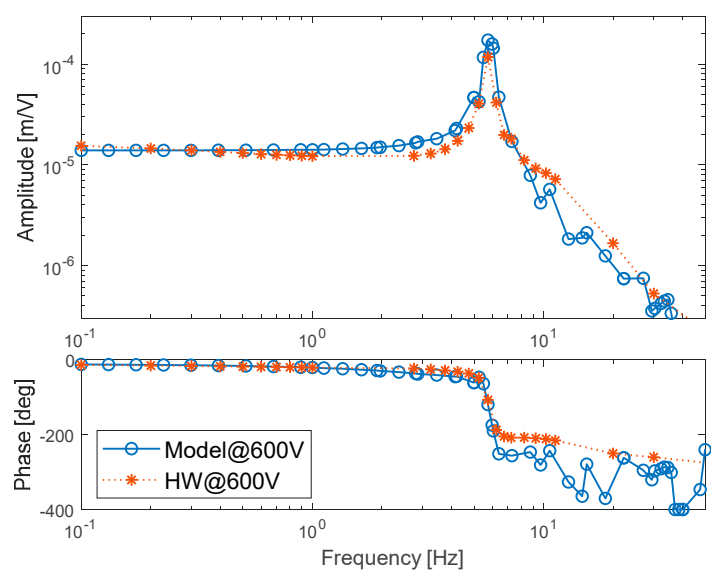

(a)

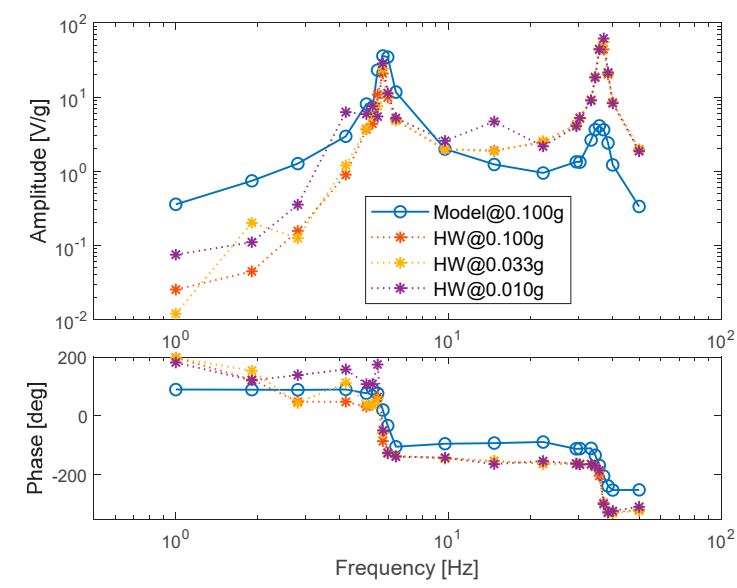

(b)

Figure 6. Model parameters' tuning via frequency-domain responses: (a) deformation response to voltage input; (b) stored voltage response to base acceleration input. 


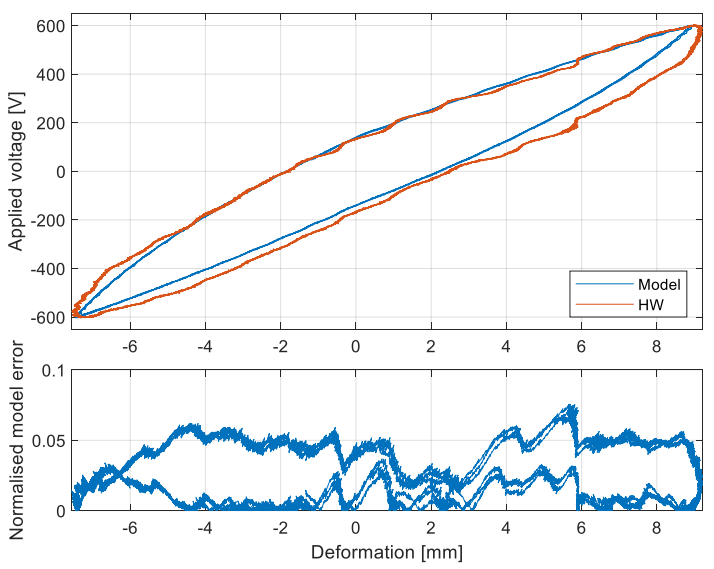

(a)

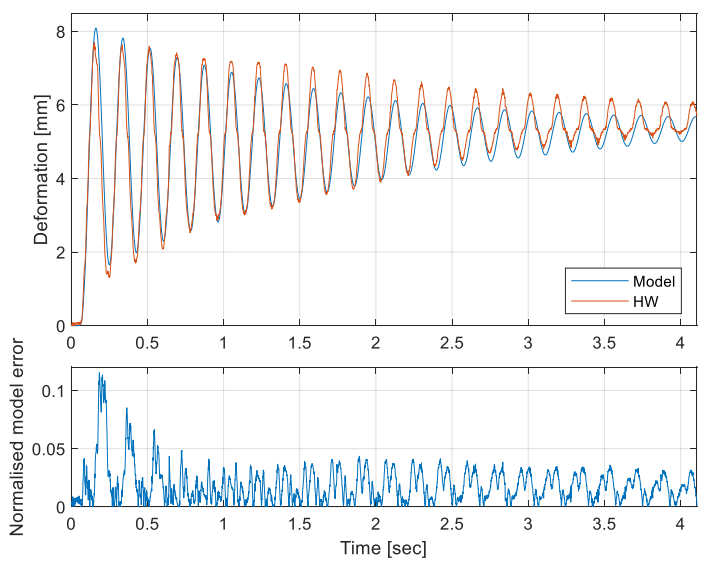

(b)

Figure 7. Validation of the model via time-domain responses: (a) hysteresis deformation loop with sinewave voltage input at $0.01 \mathrm{~Hz}$; (b) deformation response to step voltage input of $300 \mathrm{~V}$.

It is worth noting that the experimental investigation pointed out that the deformation response weakly depends on applied voltage amplitude, and no significant variation of the system dynamic behavior is observed by changing the input voltage amplitude. On the other hand, the stored voltage response strongly depends on base acceleration amplitude. For these reasons, Figure 6a reports the deformation response at $600 \mathrm{~V}$ amplitude only, while Figure $6 \mathrm{~b}$ shows the voltage storage results for different acceleration amplitudes (note that also simulation results are amplitude-dependent, but only one acceleration amplitude is given in Figure $6 \mathrm{~b}$ for the clarity of the plot).

Both experiments and simulations clearly point out that the resonant peak related to the first bending mode occurs at $5.8 \mathrm{~Hz}$, the resistance-capacitance electric dynamics induces a real pole at about $10 \mathrm{~Hz}$, while the second bending mode implies a resonance at $37 \mathrm{~Hz}$. Experiments also point out the relevant voltage storage capability of the prototype, which is characterized by an acceleration-to-voltage gain that depends on vibration amplitude and achieves $35 \mathrm{~V} / \mathrm{g}$ at $5.8 \mathrm{~Hz}$ (first resonance) and $68 \mathrm{~V} / \mathrm{g}$ at $37 \mathrm{~Hz}$ (second resonance). The behavior is well reproduced by simulations, even if the prediction accuracy in terms of stored voltage amplitude is lower at the second resonance. This is probably due to that fact that the lumped-parameters model concentrates the laminate deformations at only three points, and this implies a decrease of accuracy at higher modes, in which the deformation distribution along the laminate is more complex.

Concerning the model validation, the activity is here focused on the actuation behavior only, essentially because the model-based condition-monitoring algorithm is designed via maintenance built-in test (MBIT) simulations, when the patches work as actuators. Validation of the model addressing the sensing/energy harvesting behavior will be a future development of this work.

Preliminary comparisons between model predictions and experimental data highlighted that the prediction error of a generic system variable $(y)$ is linearly correlated to the amplitude of the variable itself, Equation (4):

$$
\left|y_{\mathrm{md}}-y_{\mathrm{hw}}\right|=e_{0 y}+k_{\text {erry }}\left|y_{\mathrm{hw}}\right|
$$

where $y_{\mathrm{md}}$ is the model prediction and $y_{\mathrm{hw}}$ is the hardware response, while $e_{0 y}$ and $k_{\text {err }} y$ are the bias and the gain characterizing the error on the variable $y$. For this reason, the evaluation of the prediction accuracy was made by normalizing the model error via Equation (5)

$$
\varepsilon_{\mathrm{my}}=\frac{\left|y_{\mathrm{md}}-y_{\mathrm{hw}}\right|}{\left|y_{\mathrm{hw}}\right|+e_{0 y} / k_{\text {erry }}}
$$


Figure 7, related to deformation responses, actually demonstrates the effectiveness of the approach, since the normalized error does not significantly vary with the deformation amplitude for both quasi-static and fast transient tests. In the hysteresis test, the normalized deformation error is roughly constant during both discharge and charge phases, being $5 \%$ of the actual deformation in the charging phase and lower than $0.5 \%$ during discharge. Similar results are noted in the step response tests, where, after the initial transient, the mean value of the normalized error is $2 \%$ of the actual deformation, and its fluctuations are limited to $2 \%$.

\subsection{Assessment of the Energy Harvesting Capability}

The experimentally-validated model of the prototype was used to assess its energy harvesting capability, aiming to support the feasibility of the self-powered system. The objective is to demonstrate that the MFC patches are capable of restoring the charge of a low-power battery, commonly used for supplying small electronic boards.

To perform the study, the open-circuit voltage characteristics $\left(v_{b}\right)$ of the 3V-65mAh Maxell ML2032 Li-ion rechargeable battery (Figure $8 \mathrm{a},[55])$ are used to calculate the equivalent capacitance $\left(C_{b}\right)$ of the Thevenin model of the battery (Figure 8b, [56]), Equation (6):

$$
C_{b}=-\frac{\partial q_{d}}{\partial v_{b}} \Rightarrow C_{b}=C_{b}\left(q_{d}\right)=C_{b}\left(v_{b}\right)
$$

where $q_{d}$ is the discharged capacity of the battery in Amp.sec.

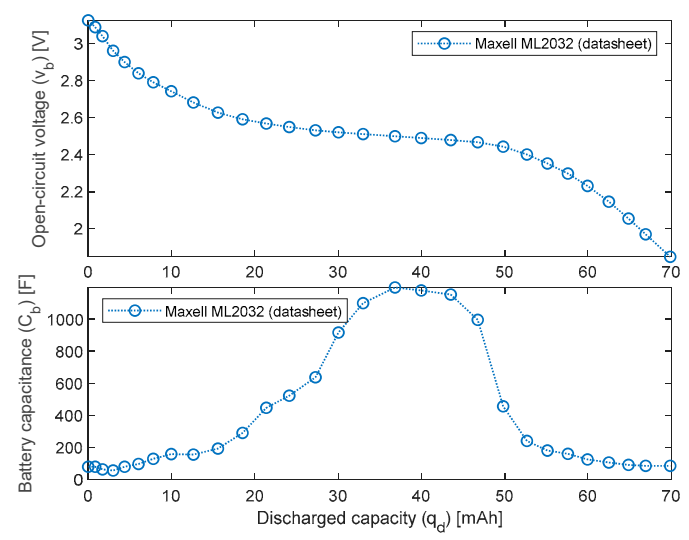

(a)

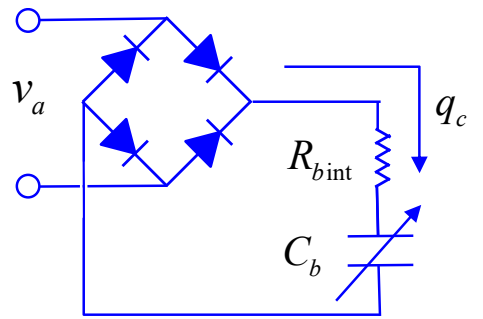

(b)

Figure 8. Energy harvesting simulation: (a) Maxell ML2032 Li-ion rechargeable battery characteristics [55]; (b) Thevenin battery model connected to the patches' voltage output [56].

Once defined, the maximum capacity of the battery $\left(q_{\max }\right)$ and its initial charge $\left(q_{0}\right)$, the battery charge $\left(q_{b}\right)$ is expressed by Equation (7):

$$
q_{b}=q_{\max }-q_{d}=q_{\max }-q_{0}+q_{c}
$$

and the battery charge dynamics obtained through the rectified MFC system voltage output $\left(v_{a}\right)$ is provided by Equation (8):

$$
v_{b}+R_{b i n t} \dot{q}_{b}=\left|v_{a}\right|
$$

By formulating the charge rate $\left(\dot{q}_{b}\right)$ as a function of the battery voltage and voltage rate,

$$
q_{b}=C_{b}\left(v_{b}\right) v_{b} \Rightarrow \dot{q}_{b}=\left(C_{b}+\frac{\partial C_{b}}{\partial v_{b}} v_{b}\right) \dot{v}_{b}=\left(C_{b}-\frac{\partial^{2} q_{d}}{\partial v_{b}^{2}} v_{b}\right) \dot{v}_{b}
$$


we finally obtain the nonlinear first-order model describing the charging behavior:

$$
\dot{v}_{b}=\frac{\left|v_{a}\right|-v_{b}}{R_{b \text { int }}\left[C_{b}\left(v_{b}\right)-\frac{\partial^{2} q_{d}}{\partial v_{b}{ }^{2}} v_{b}\right]}
$$

An example of the dynamics of the battery charge operated by the MFC patches is reported in Figure 9, where the simulation is carried out by imposing a $0.10 \mathrm{~g}$ sinusoidal base acceleration $\left(\ddot{z}_{0}\right.$ in Equations (1)-(3)) at $5.8 \mathrm{~Hz}$ (first resonance), and by assuming an internal battery resistance $\left(R_{b}\right.$ int $)$ of 1 $\mathrm{Ohm}$. It is worth noting that the prototype system is capable of harvesting the energy coming from the mechanical vibrations, and to restore the battery charge within $10 \mathrm{~min}$ (starting from a completely discharged battery, i.e., 2 V).

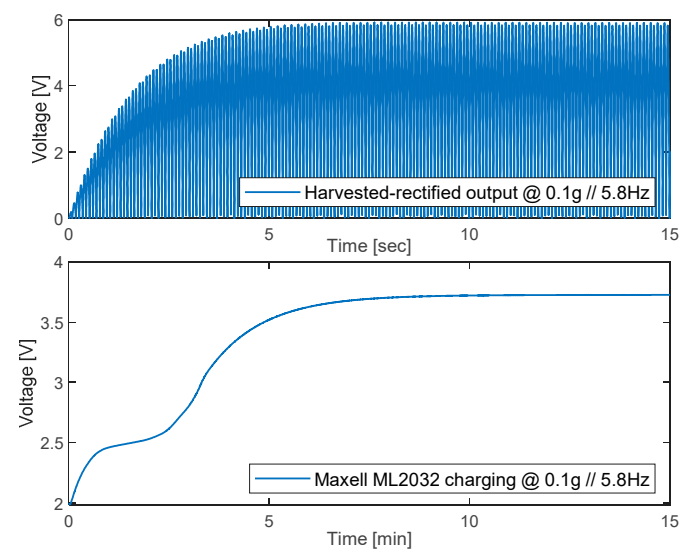

Figure 9. Energy harvesting simulation with sinusoidal base acceleration input $\left(R_{b}\right.$ int $\left.=1 \mathrm{Ohm}\right)$.

\section{System Condition Monitoring}

The experimentally-validated model of the prototype was finally used to test a model-based condition-monitoring algorithm developed by the authors [40,57-61], in order to assess the system applicability to SHM systems. In model-based condition-monitoring approaches, the detection of faults or anomalies is actually performed by evaluating the deviation of hardware responses from the predictions of a system model related to normal operating conditions.

\subsection{Condition-Monitoring Algorithm}

The proposed condition-monitoring logic, schematically reported in terms of flow chart in Figure 10, generates a fault flag (Fault $\mathrm{m}_{\mathrm{mon}}$, set to 1 in case of detection of detected anomalies) by elaborating the normalized model error $\left(\varepsilon_{\text {mon }}\right)$ sampled at the monitoring frequency $\left(f_{\text {mon }}\right)$. If the normalized error exceeds a threshold $\left(\varepsilon_{t h}\right)$, a fault counter (count ${ }_{\text {mon }}$ ) is increased by 2; if the threshold is not exceeded, the fault counter is decreased by 1 when it is positive at the previous step, otherwise it is held to 0 . The fault or anomaly is detected when the fault counter exceeds a pre-defined value $\left(\right.$ count $\left._{\max }\right)$, a parameter which basically defines the fault latency of the algorithm. 


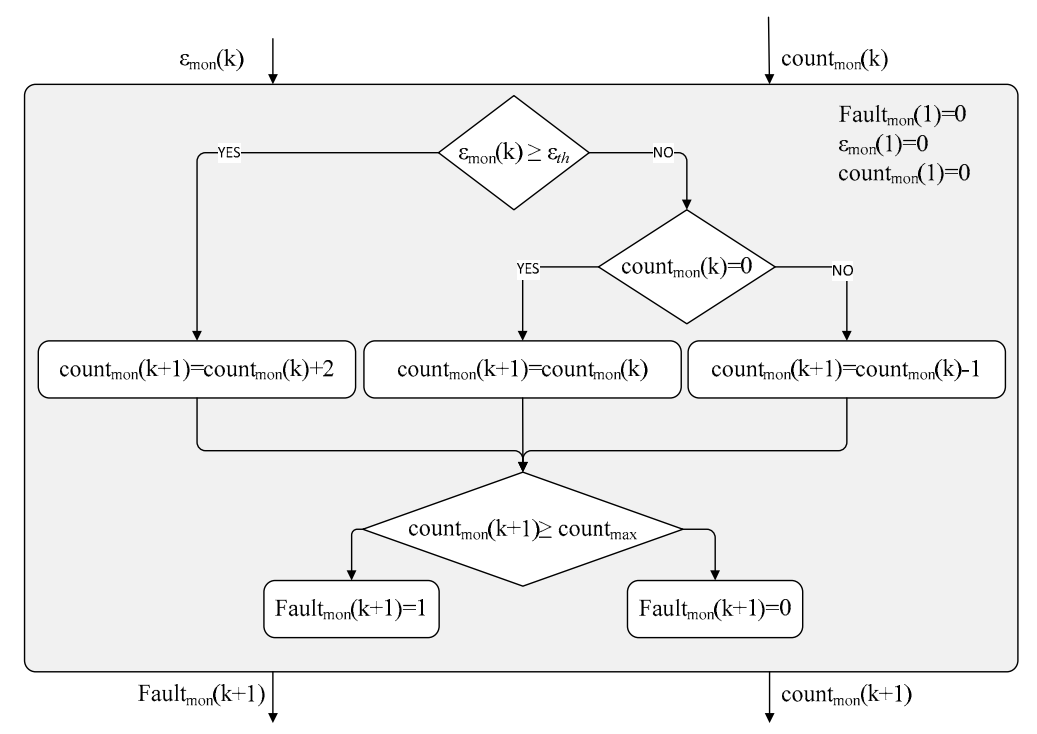

Figure 10. Flow chart of the condition-monitoring logic.

In the present study, the monitored variable is the displacement of the laminate tip due to the bending deformation $\left(z_{3}\right.$ in Equations (1)-(3)), so the normalized model error is given by Equation (5), where $e_{0}=0.75 \mathrm{~mm}$ and $k_{\text {err } z}=0.075$.

$$
\varepsilon_{\mathrm{mon}}=\frac{\left|z_{3 \mathrm{md}}-z_{3 \mathrm{hw}}\right|}{\left|z_{3 \mathrm{hw}}\right|+e_{0 z} / k_{\text {errz }}}
$$

\subsection{Maintenance Built-in-Test Simulations}

The performances of the condition-monitoring algorithm are characterized by simulating the execution of two types of maintenance built-in tests (MBITs), i.e.,

- MBIT.a: response to sinewave voltage input at $0.1 \mathrm{~Hz}$ and $600 \mathrm{~V}$ (quasi-static test, Figure 7);

- $\quad$ MBIT.b: response to step voltage input with $300 \mathrm{~V}$ amplitude (fast transient test, Figure 7).

It is worth noting that, especially for the assessment of the transient response, several types of tests were studied [40], by varying both amplitude and waveform of the input signal, and the MBIT.b demonstrated a good balance between false alarms rejection and fault detection capability.

Once defined, the monitoring frequency $\left(f_{\text {mon }}\right)$, the error threshold $\left(\varepsilon_{t h}\right)$, and the fault counter threshold (count $\mathrm{max}_{\mathrm{x}}$ ), the algorithm performances were characterized as follows:

i. for a subset of relevant system parameters (par), an acceptable range of deviations from the nominal behavior is defined. In this work, par $=\left(k_{3}, \alpha_{h}, \beta_{h}\right)$, and this selection was made because the hysteresis parameters basically affect the low-frequency behavior, while the tip stiffness also impacts the high-frequency range, by varying the location of structural resonances;

ii. a model of the "degraded" hardware is obtained from the experimentally-validated model, by injecting uniformly-distributed random deviations on the selected model parameters;

iii. MBIT. $a$ and MBIT.b are simulated by executing the condition-monitoring algorithms;

iv. steps $i i$ and $i i$ are repeated for $N$ times, to cumulate a statistical database.

Figure 11 shows the results of the performance characterization of a condition-monitoring algorithm with the parameters reported in Table 3, by executing 100 simulations on each range of $10 \%$ deviations, in terms of number of detected BIT faults (upper plots) and BIT fault probability (lower plots) as functions of the deviation range. 

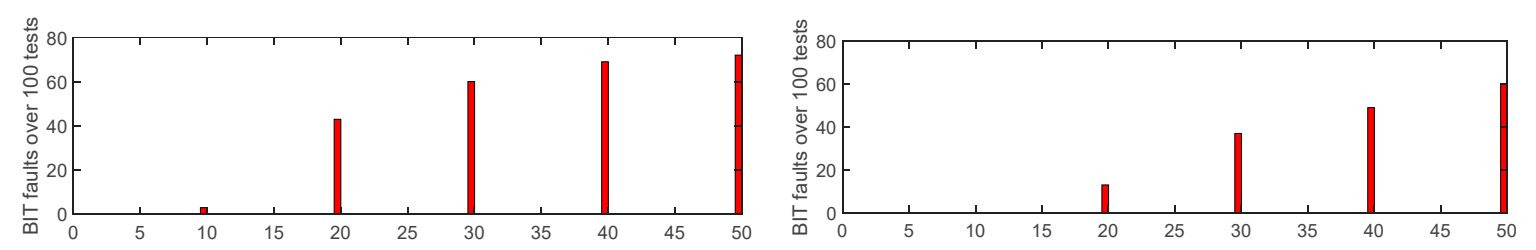

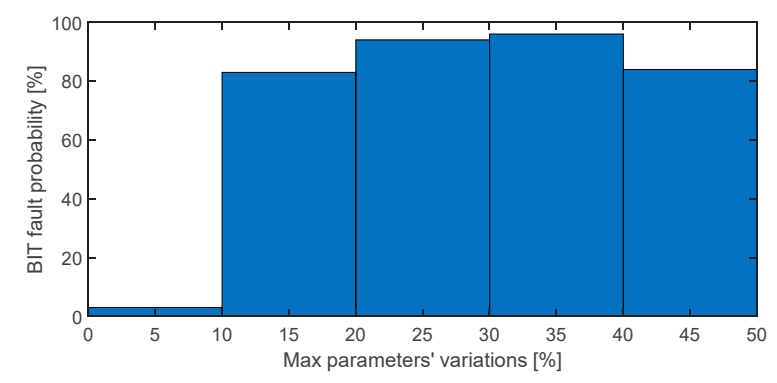

(a)

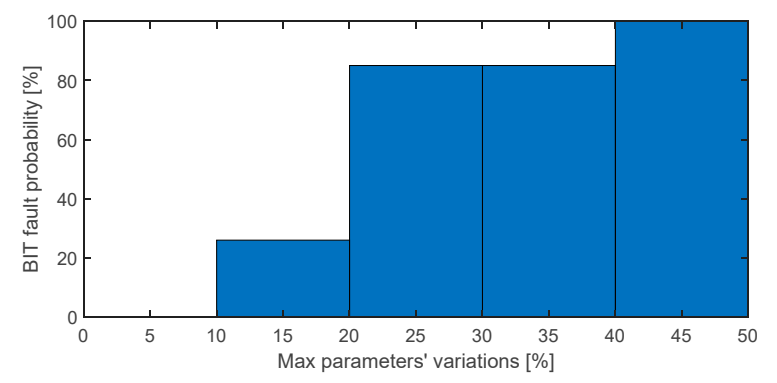

(b)

Figure 11. Performances of the condition-monitoring algorithm: (a) MBIT.a; (b) MBIT.b.

Table 3. Condition-monitoring algorithm parameters.

\begin{tabular}{cccc}
\hline Symbol & Definition & Unit & Value \\
\hline$f_{\text {mon }}$ & Monitoring frequency & $\mathrm{Hz}$ & 100 \\
$\varepsilon_{t h}$ & Normalized error threshold & - & 0.225 \\
count $_{\max }$ & Fault counter threshold & - & 200 \\
\hline
\end{tabular}

Depending on the monitoring objectives, both MBIT.a and MBIT.b effectively support the maintenance. If the objective is to minimize the performance deviations, MBIT. $a$ is more suitable, because its BIT fault probability is $83 \%$ for deviations from $10 \%$ to $20 \%$, and it increases up to $94 \%$ for deviations from $20 \%$ to $30 \%$ (Figure 11a). On the other hand, if the objective is to accept limited performance deviations, MBIT.b is better because no BIT faults occur for deviations up to $10 \%$, while the BIT fault probability is $85 \%$ for deviations from $20 \%$ to $40 \%$, and $99 \%$ for deviations from $40 \%$ to $50 \%$ (Figure 11b). Clearly, the combined use of the two MBITs would enhance the entire process by minimizing false alarms and undetected anomalies. With particular reference to the false alarms rejection, it is worth noting that the monitoring performances were not characterized in the presence of measurements' noise, because the noise impact on MBITs is expected to be minor (maintenance is performed in a controlled environment). On the other hand, the effects of noise are expected to be more relevant for in-flight monitoring algorithms (not addressed by this work).

\section{Conclusions}

A prototype of a self-powered SHM system made of a cantilevered composite laminate with six MFC patches was developed, and experimentally characterized in terms of actuation, sensing, and energy harvesting capabilities. A nonlinear dynamic model of the system, including piezoelectric hysteresis and three bending deformation modes, was developed starting from physical first principles, and validated with experiments. High fidelity was obtained in terms of deformation predictions (maximum normalized errors lower than $5 \%$ of the actual deformation), while the accuracy on stored voltage, though very good at the first resonance of the laminate $(5.8 \mathrm{~Hz})$, was lower at the second resonance $(37 \mathrm{~Hz})$. The results demonstrate the feasibility of a self-powered SHM system using the MFC technology, since the acceleration-to-voltage gain of the prototype is $35 \mathrm{~V} / \mathrm{g}$ at the first resonance, and it achieves $68 \mathrm{~V} / \mathrm{g}$ at the second resonance. The experimentally-validated model was then used to assess the energy harvesting capability of the prototype system, by demonstrating that the MFC patches are capable of restoring the charge of the 3V-65mAh Maxell ML2032 Li-ion rechargeable battery 
(commonly used for supplying small electronic boards). In particular, by imposing a $0.10 \mathrm{~g}$ sinusoidal base acceleration at $5.8 \mathrm{~Hz}$, and assuming an internal battery resistance of $1 \mathrm{Ohm}$, the system is capable of harvesting the energy coming from the mechanical vibrations, and to restore the battery charge within $10 \mathrm{~min}$ (starting from complete discharge, i.e., $2 \mathrm{~V}$ ).

Finally, the model is used to test a model-based condition-monitoring algorithm developed by the authors, by simulating two specifically-designed maintenance built-in tests. The "degraded" behavior was obtained from the "nominal" model, by injecting uniformly-distributed random deviations on relevant system parameters (the laminate stiffness and the hysteresis model coefficients), and 500 built-in-test simulations were performed. The results demonstrate that, with a combined use of the two proposed MBITs, the condition-monitoring algorithm effectively supports maintenance by checking the correspondence of performance to the nominal behavior as well as by detecting anomalies (BIT fault probability is $94 \%$ for deviations from $20 \%$ to $30 \%$, and $99 \%$ for deviations from $40 \%$ to $50 \%$ ).

In the paper, the model validation is focused on the actuation behavior, because the model-based condition-monitoring algorithm is designed via MBIT simulations when the patches work as actuators. Validation of the model addressing the sensing/energy harvesting behavior will be a future development of this work.

Author Contributions: The individual contributions of the authors to the present research article is here detailed. Conceptualization, resources, supervision, and funding acquisition: M.R.C. and G.D.R.; methodology, investigation, validation, formal analysis, and visualization: G.D.R.; software and data curation: B.L.; writing-original draft preparation, review and editing: G.D.R. and B.L.; project administration: M.R.C. All authors have read and agreed to the published version of the manuscript.

Acknowledgments: The authors wish to thank Roberto Galatolo from University of Pisa, who contributed to the preliminary conceptualization of the research, and Giuseppe Mattei and Alessandro Matera, who contributed to the initial development of the experimental test system during their MSc Degree Thesis in Aerospace Engineering at the University of Pisa.

Conflicts of Interest: The authors declare no conflicts of interest.

\section{References}

1. Bishop, R.; Mossi, K. High displacement, high force piezoelectric actuator and sensor. J. Acoust. Soc. Am. 1998, 104, 1828. [CrossRef]

2. Jayachandran, V.; Meyer, N.E.; Westervelt, M.A.; Sun, J.Q. Piezoelectrically driven speakers for active interior noise suppression. Appl. Acoust. 1999, 57, 263-277. [CrossRef]

3. Jayachandran, V.; King, P.; Meyer, N.E.; Li, F.J.; Petrova, M.; Westervelt, M.A.; Hirsch, S.M.; Sun, J.Q. Real-time feed forward control of low-frequency interior noise using shallow spherical shell piezoceramic actuators. Smart Mater. Struct. 1999, 8, 579-584. [CrossRef]

4. Corsaro, R.D. Lightweight low-frequency woofer for active sound control in payload fairings. In Proceedings of the 8th SPIE Annual International Symposium on Smart Structures and Materials, NDE and Health Monitoring, Newport Beach, CA, USA, 4-8 March 2001; pp. 254-258.

5. Horner, G.C.; Taleghani, B.K. Single axis piezoceramic gimbal. J. Intell. Mater. Syst. Struct. 2001, 12, $157-160$. [CrossRef]

6. Granger, R.; Washington, G.; Kwak, S.K. Modeling and control of a singly curved active aperture antenna using curved piezoceramic actuators. J. Intell. Mater. Syst. Struct. 2000, 11, 225-233. [CrossRef]

7. Marouzé, J.P.; Cheng, L. A feasibility study of active vibration isolation using THUNDER actuators. Smart Mater.Struct. 2002, 11, 854-862. [CrossRef]

8. Lee, S.; Cho, B.C.; Park, H.C.; Goo, N.S.; Yoon, K.J. Piezoelectric actuator-sensor analysis using a three-dimensional assumed strain solid element. J. Intell. Mater. Syst. Struct. 2004, 15, 329-338. [CrossRef]

9. Gao, J.X.; Cheng, L. Modelling of a high performance piezoelectric actuator assembly for active and passive vibration control. Smart Mater. Struct. 2004, 13, 384-392. [CrossRef]

10. Cox, A.; Monopoli, D.; Cveticanin, D.; Goldfarb, M.; Garcia, E. The development of elastodynamic components for piezoelectrically actuated flapping micro-air vehicles. J. Intell. Mater. Syst. Struct. 2002, 13, 611-615. [CrossRef] 
11. Doherty, K.M.; Nejhad, M.G. Performance of an active composite strut for an intelligent composite modified Stewart platform for thrust vector control. J. Intell. Mater. Syst. Struct. 2005, 16, 335-354. [CrossRef]

12. Waterfield, G. High performance pre-stressed piezoelectric bender actuator for digital valves. Ceram. Trans. 2004, 105, 467-482.

13. Munday, D.; Jacob, J. Active control of separation on a wing with conformal chamber. In Proceedings of the 39th AIAA Aerospace Sciences Meeting and Exhibit, Reno, NV, USA, 8-11 January 2001.

14. Mossi, K.M.; Bryant, R.G. Characterization of piezoelectric actuators for flow control over a wing. In Proceedings of the 9th International Conference on New Actuators (Actuator 2004), Breman, Germany, 14-16 June 2004.

15. Mane, P.; Mossi, K.; Bryant, R.G. Synthetic jets with piezoelectric diaphragms. Proc. SPIE 2005, 5761, $233-243$.

16. Mossi, K.M.; Mane, P.; Bryant, R.G. Velocity profiles for synthetic jets using piezoelectric circular actuators. In Proceedings of the 46th AIAA/ASME/ASCE/AHS/ASC Structures, Structural Dynamics and Materials Conference, Austin, TX, USA, 18-21 April 2005.

17. Kymissis, J.; Kendall, C.; Paradiso, J.A.; Gershenfeld, N. Parasitic power harvesting in shoes. In Proceedings of the 2nd IEEE International Conference on Wearable Computing, Pittsburgh, PA, USA, 19-20 October 1998.

18. Mossi, K.M.; Green, C.W.; Ounaies, Z.; Hughes, E. Harvesting energy using a thin unimorph pre-stressed benders: Geometrical effects. J. Intell. Mater. Syst. Struct. 2005, 16, 249-261. [CrossRef]

19. Ramsay, M.J.; Clark, W.W. Piezoelectric energy harvesting for bio MEMS applications. In Proceedings of the 8th SPIE Annual International Symposium on Smart Structures and Materials, NDE and Health Monitoring, Newport Beach, CA, USA, 4-8 March 2001; pp. 429-438.

20. Dutoit, N.E.; Wardle, B.L.; Kim, S. Design considerations for MEMS scale piezoelectric mechanical vibration energy harvesters. Integr. Ferroelectr. 2005, 1, 121-160. [CrossRef]

21. Soh, C.K.; Yang, Y.; Bhalla, S. Smart Materials in Structural Health Monitoring, Control and Biomechanics; Springer: Berlin/Heidelberg, Germany, 2012.

22. Arnau, A.; Soares, D. Piezoelectric Transducers and Applications; Springer: Berlin/Heidelberg, Germany, 2009.

23. Park, S.; Yun, C.B.; Inman, J. Structural health monitoring using electro-mechanical impedance sensors. Fatigue Fract. Eng. M. 2008, 31, 714-724. [CrossRef]

24. Na, W.S.; Baek, J. A review of the piezoelectric electromechanical impedance-based structural health monitoring technique for engineering structures. Sensors 2018, 18, 1307. [CrossRef]

25. Mossi, K.M.; Scott, L. Sensor measurements for diagnostic equipment. In Proceedings of the 1st World Congress on Biomimetics and Artificial Muscles, Albuquerque, NM, USA, 9-12 December 2002.

26. Bent, A.A.; Hagood, N.W. Piezoelectric fiber composite with interdigitated eletrodes. J. Intell. Mater. Syst. Struct. 1997, 8, 903-919. [CrossRef]

27. Kovalovs, A.; Barkanov, E.; Gluhihs, S. Active control of structures using macro-fiber composite (MFC). J. Phys. Conf. Ser. 2007, 93, 012034. [CrossRef]

28. Prasath, S.S.; Arockiarajan, A. Effective electromechanical response of macro-fiber composite (MFC): Analytical and numerical models. Int. J. Mech. Sci. 2013, 77, 98-106. [CrossRef]

29. Zhang, S.Q.; Li, Y.X.; Schmidt, R. Modeling and simulation of macro-fiber composite layered smart structures. Compo. Struct. 2015, 126, 89-100. [CrossRef]

30. Zhang, J.; Tu, J.; Li, Z.; Gao, K.; Xie, H. Modeling on actuation behavior of Macro-Fiber Composite laminated structures based on sinusoidal shear deformation theory. Appl. Sci. 2019, 9, 2893. [CrossRef]

31. Moses, R.W.; Pototzky, A.S.; Henderson, D.A.; Galea, S.C.; Manokaran, D.S.; Zimcik, D.G.; Wickramasinghe, V.; Pitt, D.M.; Gamble, M.A. Actively controlling buffet-induced excitations. In Proceedings of the RTO/AVT-123 Symposium on Flow Induced Unsteady Loads and the Impact on Military Applications, Budapest, Hungary, 25-29 April 2005.

32. Schiller, N.H.; Perey, D.F.; Cabell, R.H. Development of a practical broadband active vibration control system. In Proceedings of the 2011 ASME International Mechanical Engineering Congress and Exposition, Denver, CO, USA, 11-17 November 2011; pp. 683-690.

33. Giles, A.M.; Machin, J.T.; Geriguis, J.A. Method and Apparatus for Inhibiting Formation of and/or Removing Ice from Aircraft Components. U.S. Patent No. 9,327,839, 3 May 2016.

34. Molinari, G.; Quack, M.; Arrieta, A.F.; Morari, M.; Ermanni, P. Design, realization and structural testing of a compliant adaptable wing. Smart Mater. Struct. 2015, 10, 105027. [CrossRef] 
35. Paradies, R.; Ciresa, P. Active wing design with integrated flight control using piezoelectric macro fiber composites. Smart Mater. Struct. 2009, 3, 035010. [CrossRef]

36. Chiarelli, M.R.; Binante, V.; Botturi, S.; Massai, A.; Kunzmann, J.; Colbertaldo, A.; Romano, D.G. On the active deformations of hybrid specimens. Aircr. Eng. Aerosp. Tec. 2016, 5, 676-687. [CrossRef]

37. Chiarelli, M.R.; Cozzolino, A.; Kunzmann, J.; Lanzi, L. Feasibility Analysis on the Use of Piezo-Electric Materials as Actuators of Thin Walled Active Structures. Available online: http://www.futurewings.eu/ FILES_linked/Deliverable_D_1_1Pisa_publishable.pdf (accessed on 8 February 2020).

38. Prosser, W.H.; Wu, M.C.; Allison, S.G.; DeHaven, S.L.; Ghoshal, A. Structural health monitoring sensor development at NASA Langley Research Center. In Proceedings of the International Conference on Computational \& Experimental Engineering and Sciences (ICCES '03), Corfù, Greece, 25-29 July 2003.

39. Roellig, M.; Schubert, L.; Lieske, U.; Boehme, B.; Frankenstein, B.; Meyendorf, N. FEM assisted development of a SHM-piezo-package for damage evaluation in airplane components. In Proceedings of the 11th International Thermal, Mechanical \& Multi-Physics Simulation, and Experiments in Microelectronics and Microsystems (EuroSimE), Bordeaux, France, 26-28 April 2010.

40. Di Rito, G.; Luciano, B.; Chiarelli, M.R.; Galatolo, R. Condition monitoring of a morphing laminate with MFC piezoelectric patches via model-based approach. In Proceedings of the 6th IEEE International Workshop on Metrology for AeroSpace (MetroAeroSpace), Turin, Italy, 19-21 June 2019; pp. 241-246.

41. Green, C.; Mossi, K.M.; Bryant, R.G. Scavenging energy from piezoelectric materials for wireless sensor applications. In Proceedings of the 2005 ASME International Mechanical Engineering Congress and Exposition, Orlando, FL, USA, 5-11 November 2005; pp. 93-99.

42. Yuan, J.; Xie, T.; Shan, X.; Chen, W. Experimental study on a self-powered piezoelectric sensor under vibration environment. In Proceedings of the 18th IEEE International Symposium on the Applications of Ferroelectrics, Xian, China, 23-27 August 2009.

43. Xia, H.; Xia, Y.; Ye, Y.; Qian, L.; Shi, G. Simultaneous wireless strain sensing and energy harvesting from multiple piezo-patches for Structural Health Monitoring applications. In Proceedings of the 11th International Thermal, Mechanical \& Multi-Physics Simulation, and Experiments in Microelectronics and Microsystems (EuroSimE), Bordeaux, France, 26-28 April 2010.

44. Chao, P.C.P. Energy harvesting electronics for vibratory devices in self-powered sensors. IEEE Sens. J. 2011, 11, 3106-3121. [CrossRef]

45. Álvarez-Carulla, A.; Colomer-Farrarons, J.; López-Sánchez, J.; Miribel-Català, P. An adaptative self-powered energy harvester strain sensing device based of mechanical vibrations for structural health monitoring applications. In Proceedings of the 25th International Symposium on Industrial Electronics (ISIE), Santa Clara, CA, USA, 8-10 June 2016; pp. 638-644.

46. Mayergoyz, I.D. The classical Preisach model of hysteresis and reversibility. J. Appl. Phys. 1991, 8, $4602-4604$. [CrossRef]

47. Brokate, M.; Sprekels, J. Hysteresis and Phase Transitions; Springer: New York, NY, USA, 1996.

48. Sun, L.; Ru, C.; Rong, W.; Chen, L.; Kong, M. Tracking control of piezoelectric actuator based on a new mathematical model. J. Micromech. Microeng. 2004, 11, 1439.

49. Xue, X.; Chen, L.; Wu, X.; Sun, Q. Study on electric-mechanical hysteretic model of macro-fiber composite actuator. J. Intell. Mater. Syst. Struct. 2014, 12, 1469-1483.

50. Kamlah, M.; Jiang, Q. A constitutive model for ferroelectric PZT ceramics under uniaxial loading. Smart Mater. Struct. 1999, 4, 441. [CrossRef]

51. Goldfarb, M.; Celanovic, N. Modeling piezoelectric stack actuators for control of micromanipulation. IEEE Control Syst. Mag. 1997, 3, 69-79.

52. Bouc, R. Forced vibration of mechanical systems with hysteresis. In Proceedings of the 4th Conference on Non-Linear Oscillation, Prague, Czechoslovakia, 5-9 September 1967.

53. Wen, Y.K. Method for random vibration of hysteretic systems. J. Eng. Mech. Div. 1976, 2, 249-263.

54. Ikhouane, F.; Rodellar, J. Systems with Hysteresis: Analysis, Identification and Control Using the Bouc-Wen Model; John Wiley \& Sons: Hoboken, NJ, USA, 2007.

55. Data SheetModel. Available online: http://www.maxell.com.tw/images/uploads/2015/05/ML2032_DataSheet_ table.pdf (accessed on 8 February 2020).

56. Barreras, J.V.; Schaltz, E.; Andreasen, S.J.; Minko, T. Datasheet-based modeling of Li-Ion batteries. In Proceedings of the 2012 IEEE Vehicle Power and Propulsion Conference, Seoul, Korea, 9-12 October 2012. 
57. Di Rito, G.; Galatolo, R. Experimental and theoretical study of the electrical failures in a fault-tolerant direct-drive servovalve for primary flight actuators. Proc. IMechE Part I: J. Syst. Control Eng. 2008, 222, 757-769. [CrossRef]

58. Di Rito, G.; Schettini, F. Health monitoring of electromechanical flight actuators via position-tracking predictive models. Adv. Mech. Eng. 2018, 10, 1-12. [CrossRef]

59. Di Rito, G.; Schettini, F.; Galatolo, R. Model-based health-monitoring of an electro-mechanical actuator for unmanned aerial system flight controls. In Proceedings of the 4th IEEE International Workshop on Metrology for AeroSpace (MetroAeroSpace), Padua, Italy, 21-23 June 2017; pp. 481-490.

60. Di Rito, G.; Schettini, F.; Galatolo, R. Self-monitoring electro-mechanical actuator for medium altitude long endurance unmanned aerial vehicle flight controls. Adv. Mech. Eng. 2016, 8, 1-11. [CrossRef]

61. Di Rito, G.; Schettini, F.; Galatolo, R. Model-based prognostic health-management algorithms for the freeplay identification in electromechanical flight control actuators. In Proceedings of the 5th IEEE International Workshop on Metrology for AeroSpace (MetroAeroSpace), Rome, Italy, 20-22 June 2018; pp. 340-345.

(C) 2020 by the authors. Licensee MDPI, Basel, Switzerland. This article is an open access article distributed under the terms and conditions of the Creative Commons Attribution (CC BY) license (http://creativecommons.org/licenses/by/4.0/). 